\title{
MONITORING AND ANALYZING THE GEOSPATIAL PATTERNS OF THE PEARL RIVER DELTA (PRD) FROM 1960 TO 2012
}

\author{
Jin Wang ${ }^{1,2}$, Zhifeng $\mathrm{Wu}^{3, *}$, Shaoying $\mathrm{Li}^{3}$, Zheng $\mathrm{Cao}^{1,2}$ \\ ${ }^{1}$ Guangzhou Institute of Geochemistry, Chinese Academy of Science, P. R. China - egmontwj@gmail.com (J.W.); jnczdl@163.com \\ (Z.C.) \\ ${ }^{2}$ University of Chinese Academy of Sciences, P. R. China \\ ${ }^{3}$ School of Geographical Sciences, Guangzhou University, P. R. China - gzuwzf@163.com (Z.W.); 1sy_0130@163.com (S.L.)
}

ICWG II/III

KEY WORDS: Geographical Spatial Patterns, Coastal Environment; Landuse, Coastline

\begin{abstract}
:
The Geospatial Patterns Pearl River Delta (PRD), one of the most economically-important and fastest-growing regions in China, have changed remarkably and continuously during the past decades. In this research, the change of landuse, coastline during 1960 2012 were closely investigated to provide better description and explanation of the geospatial pattern. And the relationships between them were explored. Finally, the impact that urban expansion brought to the coastal environment was quantitatively analyzed. The main remarks of this research are summarized into the following points: (1) In PRD, construction land expanded 33 times. In the meantime, the area of forest and farmland decreased $47.53 \%$ and $56.70 \%$, respectively. (2) The land demand for agricultural development was the key factor that changed coastline in PRD before 2000. Since 2000, land demand for urban construction has been the key factor that changed coastline in PRD. (3) During 1960 to 2012, the length of coastline in PRD increased from $1134.95 \mathrm{~km}$ to $1508.02 \mathrm{~km}$ with an increasing speed of $7.17 \mathrm{~km}$ per year. Relatively, the coastline changed more obvious in three periods (2004 to 2006, 2006 to 2008 and 2008 to 2010). (4) The type of coastline changed remarkably from 1960 to 2012. 82.94\% of the natural coastline in PRD disappeared until 2012. Known from this research, the geospatial patterns of the PRD changed remarkably during 1960 to 2012 , mainly driven by human activities. The coastal environment is facing serious risks and challenges under the rapid process of urbanization.
\end{abstract}

\section{INTRODUCTION}

Pearl River Delta (PRD) is one of the most prosperous and fastest growing regions in China. Guangzhou, Shenzhen and other important cities located in this area. PRD is the world largest metropolitan area according to the annual report (2015) from UN-Habitat. It created nearly $10 \%$ of GDP of mainland China with only $0.57 \%$ of the land area at 2014 (Bureau 2015). The geospatial patterns of landuse and coastline remarkably changed under rapid industrialization in PRD.

The coastline is the sea-land demarcation line in coastal regions. The position and shape of the coastline exert remarkable influence on the coastal environment by changing coastal wetland, river estuary, geomorphology of the shore, coastal climate, etc (Dellepiane et al. 2004; Rasuly et al. 2010). It is one of the most important linear features on the earth's surface, which has a dynamic nature (Winarso and Budhiman 2001). In the coastal area, the change of landuse has close relationships with coastline (Freire et al. 2009). The geospatial patterns of coastline and landuse are both the key factor of the coastal environment.

In this research, the change of landuse and coastline in PRD during 1960 to 2012 was closely investigated to provide better description and explanation of the geographical spatial pattern based on RS and GIS. First, the temporal and spatial variation of landuse, coastline and coastal wetland were monitored and analyzed with the quantitative and spatial approach. Furthermore, the relationships among them were explored. Finally, the impact that urban expansion brought to the coastal environment was quantitatively analyzed.

\section{STUDY AREA \& DATA SOURCE}

The study area in this research was defined by the $10 \mathrm{~km}$ buffer zone of the coastline of PRD in 1960. Five important cities in this area are therefore covered, namely Guangzhou (GZ), Dongguan (DG), Shenzhen (SZ), Zhongshan (ZS) and Zhuhai $(\mathrm{ZH})$. With regional excellence, natural resources abundance and economic prosperity, it is the core area of Guangdong-Hong Kong-Macau Greater Bay Area, home to 120 million (Habitat 2016).

Multi-source remote sensing imageries, large-scale topographic maps and historical maps were used in this research, together with DEM data, field survey data and administrative maps as auxiliary data. The main data sources for each periods are listed in Table 1. Atmosphere correction and geometry correction were performed for all 37 imageries. Multi-temporal imagery adaptive regression model was applied for fixing the gap in Landsat 7 imageries (Zeng et al. 2013). The source data used for monitoring geospatial patterns in 1960 were topographic maps with a scale of 1:50000.

\footnotetext{
* Corresponding author
} 


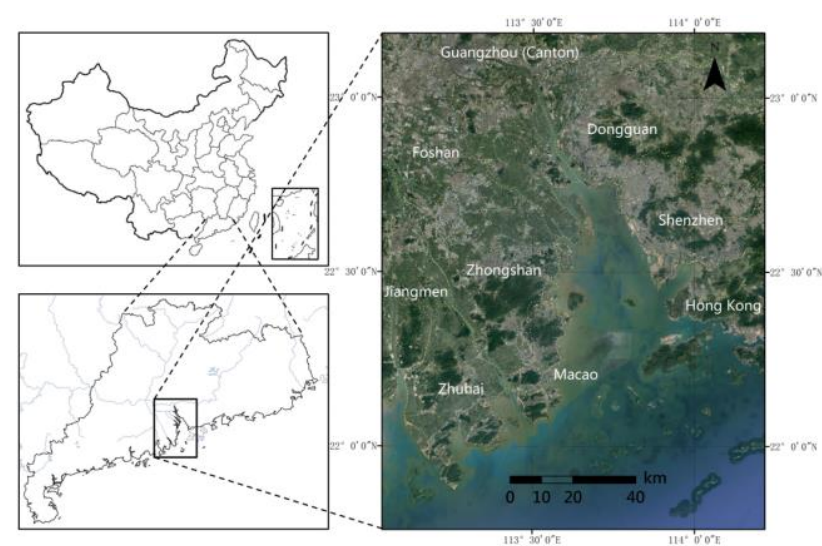

Figure 1. The location of the study area

\begin{tabular}{|c|c|c|}
\hline Year & Main data source & Resolution $(\mathrm{m})$ \\
\hline 1960 & Topographic maps & $/$ \\
1979 & Landsat 2 MSS & 78 \\
1990 & Landsat 5 TM & 30 \\
1995 & Landsat 5 TM & 30 \\
2000 & Landsat 5 TM & 30 \\
2002 & Landsat 5 TM & 30 \\
2004 & Landsat 7 ETM+ & 15 \\
2006 & SPOT5 & 2.5 \\
2008 & SPOT5 & 2.5 \\
2010 & Landsat 7 ETM+ & 15 \\
2012 & Landsat 7 ETM+ & 15 \\
\hline
\end{tabular}

Table 1. Main data source

\section{METHODOLOGY}

\subsection{Coastline}

Object-oriented (O-O) classification was used to extracting coastline from 1979 to 2012. O-O classification is a recent and evolving technology where textural and contextual/relational information is used in addition to spectral information for classifying data. It is particularly useful for extracting and mapping features from high spatial but low spectral resolution images. O-O classification is driven by an understanding of image object rather than pixels. An image object is a homogeneous group of pixels/regions that have similar spectral and/or spatial characteristics (Bhaskaran et al. 2010).

Additionally, the coastline in 1960 was extracted via visual interpret.

\subsection{Landuse}

The study area was classified into six landuse categories, including buildup area, vegetation, farmland, water body, fishery cultivation (aquaculture) and exclamation land. Supervised classification was applied for mapping the landuse of PRD in 1979 2004 and 2010 2012 from Landsat imageries. For mapping landuse of 2006 2008 from SPOT 5 imageries, O$\mathrm{O}$ classification was applied in order to take full advantage of the plentiful information of geometry, texture, topology in highresolution imagery. Landuse in 1960 was mapped by visual interpretation of topographic maps. In the post classification step, all the results of landuse were carefully corrected based on field survey and temporal consistency was examined. Finally, the results of 1960, 1979, 2006 and 2008 were resampled into $30 \mathrm{~m}$ for matching with results of other periods.

\subsection{Accuracy assessment}

400 validation points were randomly selected from the study area. To assess the accuracy of landuse classification and coastline extraction respectively, their landuse type and land/marine attribute were assigned based on field survey and high-resolution imageries. Indicated by cross validation, the landuse type of 342 points and the land/marine attribute of 379 were accurately estimated. The accuracy of landuse classification and coastline extraction is $85.5 \%$ and $94.75 \%$, respectively.

\section{RESULTS}

\subsection{Coastline change}

4.1.1 Change of coastline form

It can be shown that the length of coastline increased from $1034.22 \mathrm{~km}$ to 1508.02 at an annual increasing speed of $6.79 \mathrm{~km} / \mathrm{a}$ (Figure 2). With annual change rate of about $3 \%$ (Table 2), 2004 2010 is the most drastically changing period. In PRD, most of the coastline change was driven by anthropogenic factors, including urbanization and agriculture.

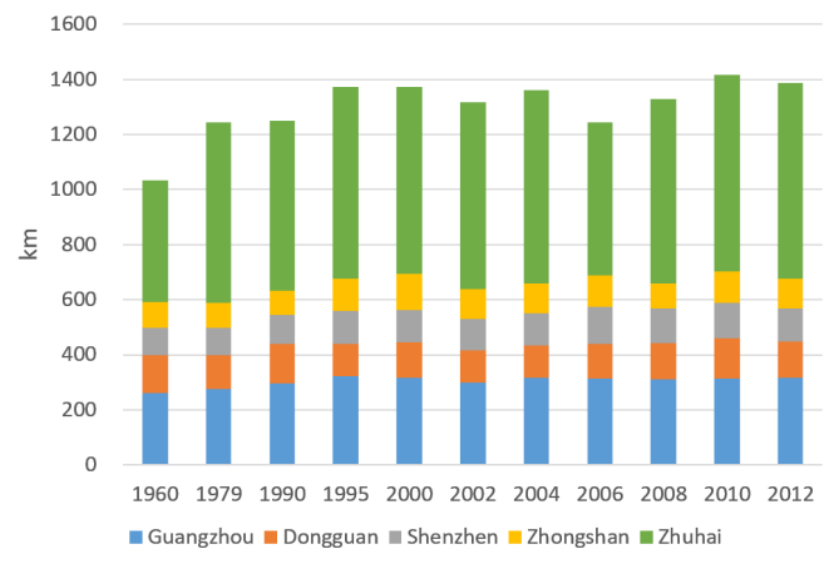

Figure 2. Change of coastline length in the PRD (1960 2012)

\begin{tabular}{|c|c|c|c|c|c|c|}
\hline & Total & GZ & DG & SZ & ZS & ZH \\
\hline $1960 ~ 1979$ & $0.90 \%$ & $0.29 \%$ & $-0.58 \%$ & $0.02 \%$ & $-0.24 \%$ & $2.10 \%$ \\
$1979 \sim 1990$ & $0.05 \%$ & $0.63 \%$ & $1.60 \%$ & $0.23 \%$ & $-0.16 \%$ & $-0.55 \%$ \\
$1990 \sim 1995$ & $2.01 \%$ & $1.80 \%$ & $-4.43 \%$ & $3.23 \%$ & $5.59 \%$ & $2.47 \%$ \\
$1995 \sim 2000$ & $-0.06 \%$ & $-0.39 \%$ & $2.10 \%$ & $-0.71 \%$ & $2.31 \%$ & $-0.48 \%$ \\
$2000 \sim 2002$ & $-1.93 \%$ & $-2.94 \%$ & $-4.41 \%$ & $-0.79 \%$ & $-9.20 \%$ & $-0.06 \%$ \\
$2002 \sim 2004$ & $1.51 \%$ & $3.21 \%$ & $-0.54 \%$ & $-0.09 \%$ & $0.68 \%$ & $1.78 \%$ \\
$2004 \sim 2006$ & $-3.45 \%$ & $-0.44 \%$ & $4.08 \%$ & $7.53 \%$ & $1.71 \%$ & $-11.06 \%$ \\
$2006 \sim 2008$ & $2.85 \%$ & $-0.80 \%$ & $2.34 \%$ & $-2.18 \%$ & $-10.72 \%$ & $9.69 \%$ \\
$2008 \sim 2010$ & $2.98 \%$ & $0.79 \%$ & $5.11 \%$ & $-0.25 \%$ & $12.94 \%$ & $3.36 \%$ \\
$2010 \sim 2012$ & $-1.19 \%$ & $0.54 \%$ & $-5.58 \%$ & $-2.52 \%$ & $-2.67 \%$ & $-0.37 \%$ \\
\hline
\end{tabular}

Table 2. The average annual change of coastline length

The coastline in the city of Zhuhai experienced the greatest change in PRD. It reached $709.51 \mathrm{~km}$ in $2012,1.61$ times of that in 1960 . From 2004 to 2008, first, it decreased sharply and then 
followed by a remarkable increase. The coastline of Zhongshan (2006 2010, 1990 1995), Shenzhen (2004 2006), Dongguan (2008 2012) also changed dramatically, all in the periods of massive construction for each city.

\subsubsection{Change of coastline type}

The extracted coastline was further divided into natural/artificial coastline according to classification criterion used in previous research (Zhu et al. 2013). The results show, 42.95\% of the coastline in PRD was natural in 1979 (Figure 3). It decreased to $20.19 \%$ in 1990 . Most of the natural coastline in the north part of PRD and Shenzhen city were converted into artificial. By 2012, almost all the coastline has become artificial. The proportion of natural coastline decreased to $6.07 \%$, all distributed in the remote area of Zhuhai city.
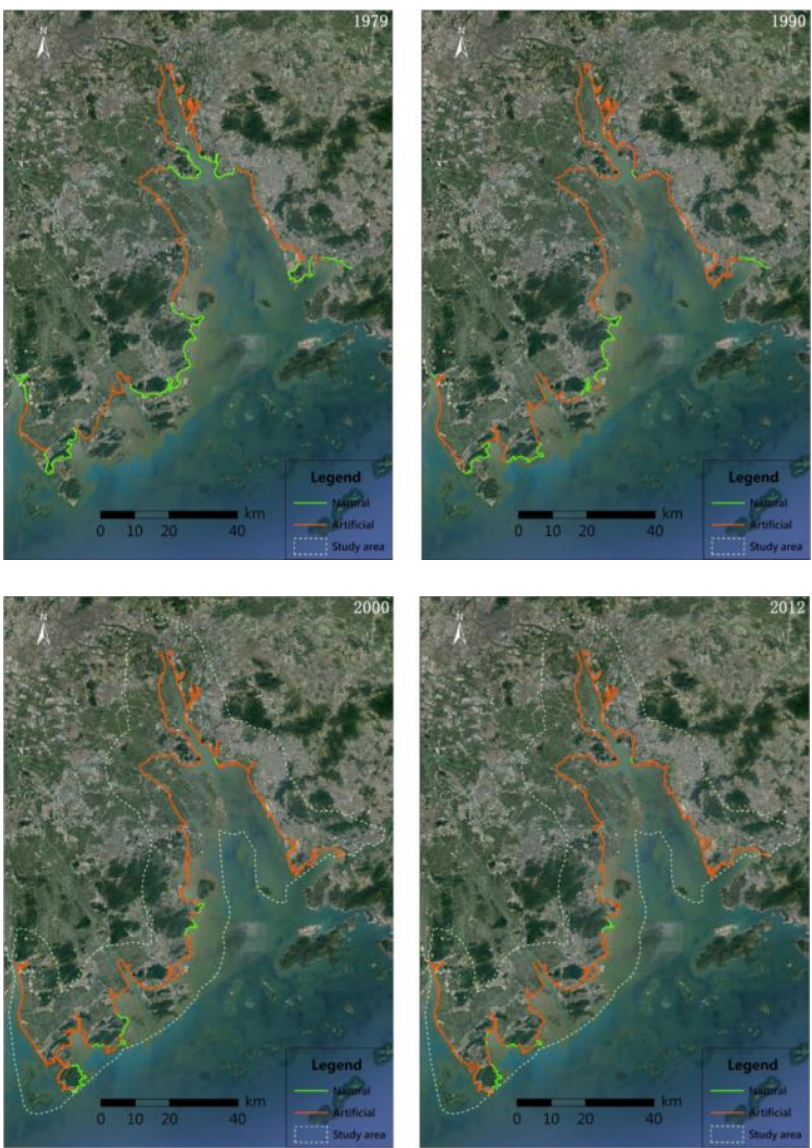

Figure 3. Change of coastline type in the PRD (1979 2012)

\subsubsection{Land expansion}

Land expansion map was produced based on the results of coastline extraction (Figure 4). It is shown that land expanded remarkably in the south part of PRD, especially Qianhai of Shenzhen and south coastal area of Zhuhai, where land area increased by $62.34 \%$ and $75.02 \%$, respectively, during 1960 2012. In Zhuhai, two islands were merged into mainland due to the reclamation of the straits in the 1980s and 2000s. In Shenzhen, the Shekou Peninsula expanded by nearly three times after 1979. Apart from the above two areas, the land area in the Nansha port area of Guangzhou also expanded sharply, from $172.34 \mathrm{~km}^{2}$ (1960) to $303.22 \mathrm{~km}^{2}$ (2012). The area of Longxue island (east of Nansha) reached $64.52 \mathrm{~km}^{2}$ in $2012,97.76$ times of that in 1960 .
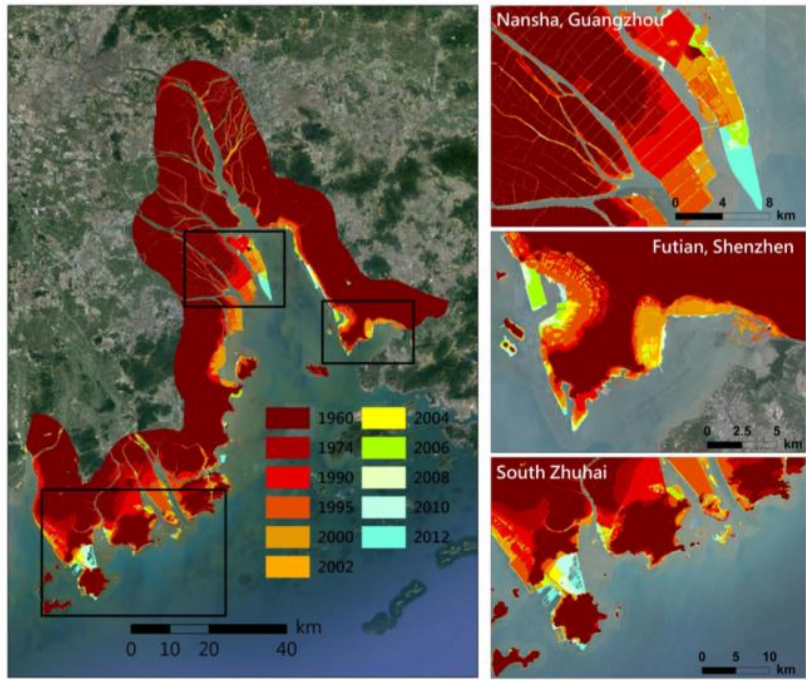

Figure 4. Land expansion map (1960 2012)

\subsection{Landuse change}

Figure 5 and Figure 6 shows the estimated results of landuse in PRD. It can be inferred from the results that: (1) the buildup area expanded 33.05 times in 52 years. Notably, it increased dramatically during 1990 1995 at an increasing speed of $22.61 \%$ per year. At the same time, the annual GDP growth rate of Guangzhou and Shenzhen, the two most important cities in south China, were $31.60 \%$ and $37.9 \%$, respectively. (2) The annual change rate of agricultural area is $-1.60 \%$ during 1960 2012. It is worth mentioning that in recent years the decreasing speed is accelerating. (3) The area of vegetation reduced sharply during 1990 1995 with an annual change rate of $-12.56 \%$. The interesting fact is that it remained stable in other periods regardless the irresistible process of urbanization. (4) The area of land for fishery cultivation (aquaculture) increased from nearly 0 (1979) to $648.06 \mathrm{~km}^{2}$ (1995) and it maintained small range fluctuation afterward. Since 1990, the reclamation has covered a considerable area of $\mathrm{PRD}$, which directly reflected the intensity of anthropogenic activities.

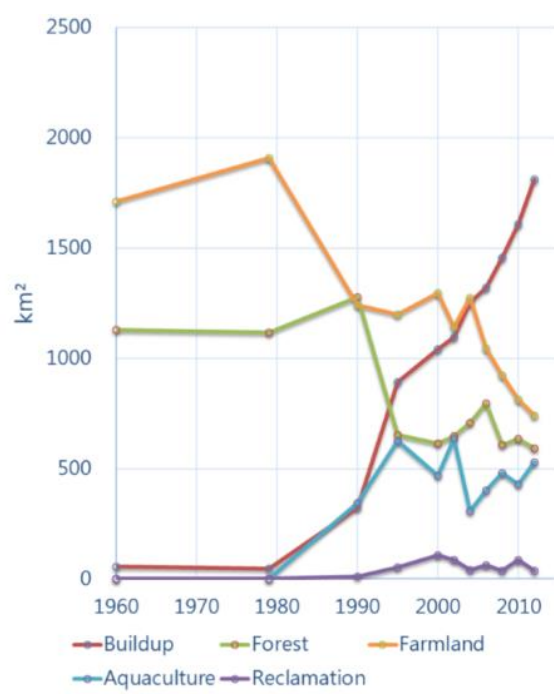

Figure 5. Statistics of landuse change in the PRD 


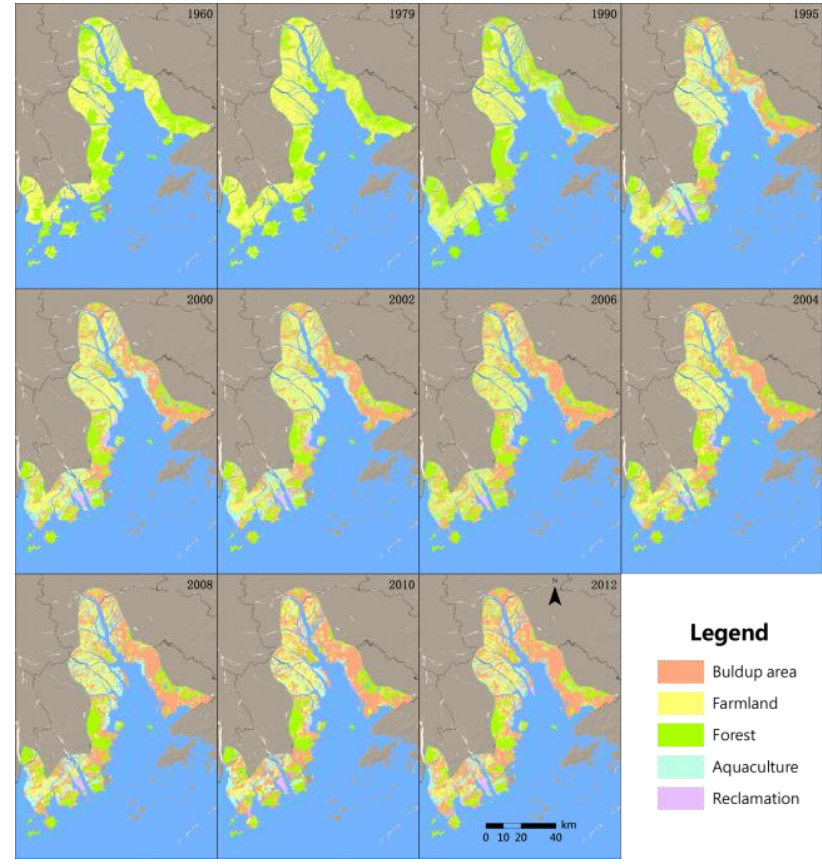

Figure 6. Landuse change in the PRD (1960 2012)

\subsection{Relationships between landuse and coastline}

Based on the results of land expansion and landuse, relationships were analyzed (Figure 7). During 1960 1979, agricultural area accounted for $61.07 \%$ of the land expansion area $\left(231.53 \mathrm{~km}^{2}\right)$. During 1979-1990, the total area of expanded land was $224.82 \mathrm{~km}^{2}$, where land for fishery cultivation accounted for $51.44 \%$. From 1990 to 2000, the total area of expanded land was $321.42 \mathrm{~km}^{2}$, where land for agriculture and fishery cultivation accounted $61.07 \%$. It can be known that the land demand for agricultural development was the key factor that changed coastline in PRD before 2000 . During 2000 2010, the total area of expanded land decreased to $100.34 \mathrm{~km}^{2}$, where construction land accounted for $51.30 \%$. Since 2000, the land demand for urban construction has been the key factor that changed coastline in PRD.

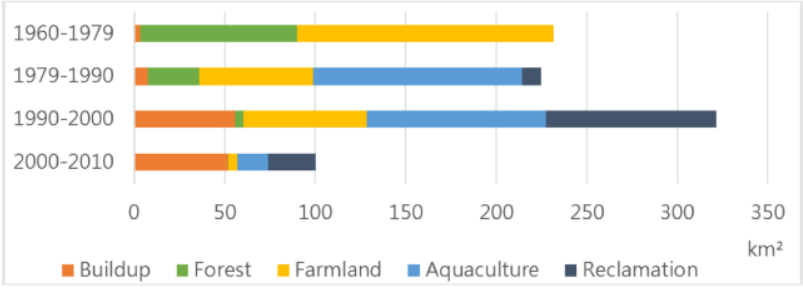

Figure 7. Landuse state in expanded land

\section{CONCLUSION}

In this research, the geospatial patterns of PRD were monitored and analyzed based on remote sensing imagery. The relationships between the change of coastline and landuse were explored with quantitative and spatial approaches. Furthermore, we also found out the reason for the dramatic changing of the coastline in PRD. The main outcomes of this research are summarized in the following points:

(1) This research demonstrated the ability of approaches based on RS and GIS for monitoring and analyzing the geospatial pattern in the coastal area, which is applicable, convenient and accurate.

(2) The period when the coastline in PRD changed the most dramatically is 2004 2010. Spatially, Guangzhou, Zhuhai and Shenzhen are the places where coastline experienced the most dramatic change.

(3) In PRD, land expanded rapidly with massive reclamation during 1960 2012, mainly driven by agricultural development (1960 2000) and urban construction (2000 2012).

\section{ACKNOWLEDGEMENTS}

This work was supported by the National Natural Science Foundation of China [41671430]; National Natural Science Foundation of China [41701204]; Guangdong Provincial Science and Technology Planning Project (No.2016A050502065).

\section{REFERENCES}

Bhaskaran, S., Paramananda, S., \& Ramnarayan, M., 2010. Perpixel and object-oriented classification methods for mapping urban features using Ikonos satellite data. Applied geography, $30,650-665$

Bureau, G.S., 2015. Guangdong Statistical Yearbook, 2014. In: China Statistics Press, Beijing.(In Chinese)

Dellepiane, S., De Laurentiis, R., \& Giordano, F., 2004. Coastline extraction from SAR images and a method for the evaluation of the coastline precision. Pattern Recognition Letters, 25, 1461-1470

Freire, S., Santos, T., \& Tenedório, J., 2009. Recent urbanization and land use/land cover change in Portugal- the influence of coastline and coastal urban centers. Journal of Coastal Research, 1499-1503

Habitat, U., 2016. Urbanization and Development Emerging Futures. World Cities Report. In: Nairobi, Kenya: United Nations Human Settlement Programme (UN-Habitat)

Rasuly, A., Naghdifar, R., \& Rasoli, M., 2010. Monitoring of Caspian sea coastline changes using object-oriented techniques. Procedia Environmental Sciences, 2, 416-426

Winarso, G., \& Budhiman, S., 2001. The potential application of remote sensing data for coastal study. In, Proc. 22nd. Asian Conference on Remote Sensing, Singapore (pp. 1-5)

Zeng, C., Shen, H., \& Zhang, L., 2013. Recovering missing pixels for Landsat ETM+ SLC-off imagery using multitemporal regression analysis and a regularization method. Remote Sensing of Environment, 131, 182-194

Zhu, J., Wang, G., Zhang, J., \& Huang, T., 2013. Remote sensing investigation and recent evolution analysis of Pearl River delta coastline. Remote Sensing for Land and Resources, $25,130-137$ 